\title{
A REVIEW ON THE IDENTITY IN IRANIAN ARCHITECTURE (CASE STUDY: NAQSH-E JAHAN SQUARE IN ESFAHAN)
}

\author{
Hamed Hayaty \\ Preceptor of Department of Architecture, Ahvaz Branch, Islamic Azad University, Ahvaz, Iran \\ hamedhayaty@yahoo.com \\ Zahra Fazeli \\ Student of Department of Architecture, Ahvaz Branch, Islamic Azad University, Ahvaz, Iran \\ Nima Alipoor \\ Student of Department of Architecture, MahshahrBranch, Islamic Azad University, Mahshahr, Iran
}

\begin{abstract}
Architecture has inherent, dynamic and progressive characteristics which are called identity, despite differences of the land that had have several impacts on it. "Identity" is from the fundamental concepts and topics that its different levels and manifestations are concerned as a serious and major need for all human beings (people and communities). One of the authentication grounds and factors of a society, especially its civilization cause, are man-made works that the most obvious manifestation of these works are the cities and consequently, urban spaces and elements. Recognition of identifier characteristics and factors of Naqsh-e Jahan square as an urban space of Iranian civilization is the main subject of this paper. In this paper, it has been examined the formation and transformation of Naqsh-e Jahan square as an urban area and an urban element from the inception to the present time. The aim of this study was to document these developments and to learn experience of interventions that have been made in this square. The research method was descriptive - analytical and based on historical texts and in some cases through field data in the place.
\end{abstract}

Keywords: Identity, Esfahan, Identity of Architecture, Iranian Architecture, Naqsh-e Jahan Square

\section{INTRODUCTION}

Socially, cities are suitable places for the formation of social institutions, promotion of cultural values, expansion and consolidation of social relations and safeguarding human values and national and local identities. So one of the authentication areas and factors and in particular the collective, cultural, historical and civilizational authentication of a society and its members are its civilizational and manmade works that one of the most obvious manifestations of these works are the cities and consequently, urban spaces and elements (Naghizadeh, 2007). Cities are indicating the identity of their creators whether as a whole or in its parts, so that the identity of a society members can be realized in intellectual and cultural terms by walking through the city. This identity means attributes and features that distinguish the city from the other, as a person is different from another person as well as a society with another society. Different elements can be considered as an identity indication of a city that each has its outward frame and specific meaning and these indications have to be checked to find out the identity of a city. Lack of identity, lack of coordination and uniformity in urban spaces are increasingly expanding todays and have made adverse landscape and an unfamiliar environment to residents and have covered all aspects of social life in urban areas, all are the results of inattention to these identity indication factors.

One very important factor among these identifying factors which is considered less todays is the relation between urban identity and human identity. This relationship is in such a way that it can be said: "urban spaces and elements in every society are manifestations of the identity of people in that community and civilization showing thought and cultural principles of the community in addition to 
its frame and appearance. So those types of cities and urban spaces and elements that can be appeared as a representation of the principles and values derived from the culture and history of the society and be continued playing the role as a specific expression of the principles and values introducing their owners and creators would be recognized as a brilliant element of that civilization and society" (Naghizadeh, 2007). And if it's not true and the principles and values are ignored, the civilization will deteriorate gradually over time.

Squares have always been an important element in the structure of historical cities and contain several types. In the meantime, urban squares have been considered as the most important and the main square of the city where the most important urban gatherings and social events were there in addition to focus of commercial, governmental and religious activities. It can be noted to the most important and most famous Iranian historic urban squares including old squares of Esfahan in the Seljuk era, Sahib-Abad square of Tabriz in Mongols era, Amir Chakhmaq square in Yazd in Timurid period, Shah square of Qazvin and Naqsh-e Jahan Square in the Safavid era and Toupkhaneh square of Tehran in Qajar period that each has had a long and rich history. Meanwhile, Naqsh-e Jahan square is considered as the most significant and the most famous historical urban squares of Iran which has been highly regarded by Iranian and foreign tourists and travelers since inception up to now.

The present study dealt with the relation of human identity and its works after addressing the sense of identity and its representation in architecture and attracted attentions to human thinking as the identifying factor for all the work, including the city and examination of the constituent elements of Naqsh-e Jahan square in Esfahan as an identity - cultural element would introduce some of its identity effects.

This study explored some of the most important historical resources and documents and has studied the status of the square as an urban element and an urban space in five major historical periods of the Safavid, Qajar, the first Pahlavi and the second Pahlavi and the Islamic Republic of Iran.

\section{IDENTITY}

First of all, it should be pointed out that identity is neutral such as culture, personality and many other concepts that must be evaluated by good and bad criteria. In other words, we have no anonymous person, object, architecture or urbanism and what exists is good identity or bad identity objects, architecture or urbanism. It has been said on the meaning of identity that: "identity means the individuation of existence and essence and what led to the identification of the person" (Moin, 1996). Thus, the identity of anything is distinguishing factor of the object with other things. Late Dehkhoda also brought within the meaning of identity that: "identity is to recognize and this is known among philosophers and theologians. Identity refers to an external existence sometimes, and sometimes refers to the nature with the recognition that includes the part truth"(Dehkhoda, 1999). Mulla Sadra knew identity of any creature as the specific way of its existence: the identity of any creature includes as the specific way of its existence, the identity is unique in human that is regarded to the different aspects. Individuals have characteristics by which they are distinct from each other and character unity will remain in them to the end of life which is identity (Eghbali, 1999). Amid dictionary spoke about the identity as "including substantial attributes"and Moin dictionary defined identity as "what helps identifying a person or an object". Oxford dictionary knows the identity as whom and what a person is (Oxford, 2008). The interesting point in this context is that the identity in relation to human is not something pre-existing, but it becomes always fresh and new. The above definition implies that everything is seen around us, including the people and all the artworks, architecture and urbanism have their own identity. Identity of phenomena will be measured in different intellectual systems with different criteria and man's thinking and approach to the world around and its analysis offers a different perspective of identity. So any ideology or idea will have its own value criteria, which can be stable and unstable, and according to these values, determined or undetermined criteria would be as assessment criterion of the identity. For traditional (religious) human, identity is a belief that forms through faith in the unseen that is produced and settled by its thoughts, deeds and behavior, while modern (secular) human makes its identity by its help. The identity is unite and divine in traditional society and Motekasr and acquired in modern society. In the traditional view, the human identity is prior to its existence and the existence is prior to identity in modern views (Hojat, 2005). So if 
representing another approach to the produced works by having a particular worldview and attitude to the world and affected identity from that, for example, representing secular identity despite having religious identity; an obvious contradiction has been revealed and this lack of correlation between appearance and reality can be cited as an identity crisis, so that if separating a little from our daily lives and contemplating, it can be felt the lack of belonging to urban or architectural space that we are within it, like a plant that is not rooted in the ground.

\section{IDENTITY IN ARCHITECTURE}

The identity can be considered as an expression of culture in the environment, because places get the meaning from the human being and the human is a set of beliefs and ideas that shapes its culture and the expression and representation of the of human culture can be seen in the environment and place which is the identity. The cultural environment of city is less perceptible todays and this is not as an inspiration for artists any longer. The modern city does not provide adequate facilities for living. Streets and squares are not no longer a place for social gathering, but they are merely a means of communication. Shack, city and country do not give what are superior values for human meant social belonging and cultural products. Perhaps the space is neutral and breaks its relationship with happiness and sadness and the space is not live for us, because it has not become a system of meaningful places. Place means where we belong to and it gets meaningful only by humans' 'me' presence and humans will only have meant by having a place and there is a linking ring called the identity. So, human gives identity to the place and so does the place for the human and our environments only become meaningful social environments when offering us rich features in personal identification and this is the frame identity (vernacular architecture) that gives the place its own means and connects people with places and place and human get two integral components (Aboueie, 1998).

\section{THE RELATIONSHIP BETWEEN IDENTITY AND WORKS OF HUMAN (ARCHITECTURE AND URBANISM)}

As mentioned, the societies' worldview and culture have affected their works and identity of the works reflects the identity of individuals of the community; identity of the works also impacts on community's thought and culture and behavior and this relationship is mutual. So if the created works are from local and national thought and culture of the community and are indicated in a frame, it strengthens the vernacular identity of the community; but if these works are blind imitation of other models with different worldviews, they can gradually affect the thought and culture and identity of the community over time and will change it. Unfortunately, this effect can be clearly seen in the architecture and urbanism of today's Iran and urban spaces and contexts have no Iranian identity that reflects the native thoughts and its impact on the morale of people can be seen in fashion, consumerism, materialism and attitudes towards issues from material angles and so on. This is despite the fact that the existence of harmony of identity in architecture and urbanism in relation to human identity in past architecture and urbanism and as we know, in the past Iranian architecture and urbanism, there has not been existed a consistent unit like as today's municipalities that make people responsible for the design and implementation of elements with specific rules or those who ordered to build the city or architecture with an identity. So how is it that every city possesses a unique identity? What is the secret of identity in our past cities? One reason for this could be in the viewpoint of our ancients to the world and religious and human values and their adherence for framing (Hojat, 2005).

Iranian architecture in the past inserted all of these principles and values in its architecture and city by adherence to its principles and values and this notation has led our past architecture and urbanism towards stable unity and various municipal buildings indicate the unity and stable identity despite having different functions in terms of materials, color and total size. For example, if we look at the Islamic city from the top, we see it as a single element, but if seeing the city from the bottom on the ground, we do not see just one thing, but also the diverse elements will be seen and because our perspective is limited and we look at the view from the bottom, we can see excess and this is the unity in diversity and this point should be borne in mind that paying attention to each of the diversities can lead us to the overall unity; what is not seen in our today's architecture. For example, one of these principles and values can be found in the spirit of collectivism and attention to the collection. Since the traditional architecture build based on tradition and collective identity, traditional architectural 
monuments are in the same the form and language, as if a thousand-years architect has built all buildings (Figure 1) and since the architects of the modern era, each build according to their own tastes and personal or style identity, new architecture works are not in the same forms and language indicating diversity of their thought and taste (Figure 2). (Hojat, 2005). (Figures 3 and 4) Islam is the religion of collectivism and the council is emphasized in it and most of its customs and rituals have collective aspects. Thus, an artist who sees the world with this approach, his works belong to the collection and means among collections. God has raised the diversity of the ethnic aiming to more recognition on each other in a verse and then conducts this diversity to the unity that the Islamic art should also have the same unity and diversity.

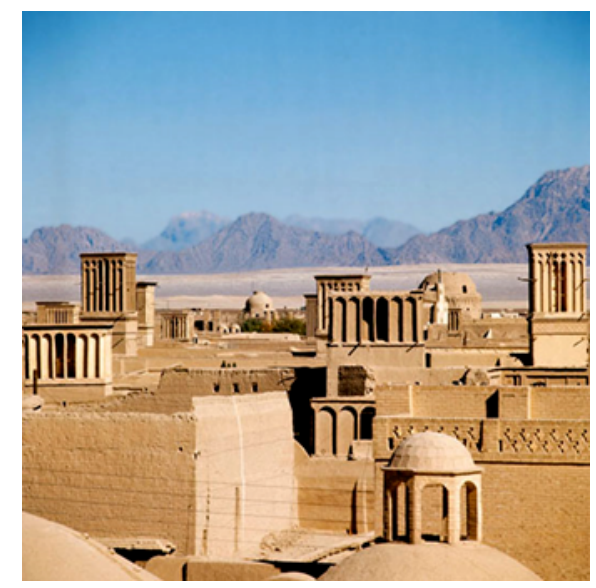

Figure 1. A view of the city of Yazd, Iran (collective identity) (Hojat, 2005).

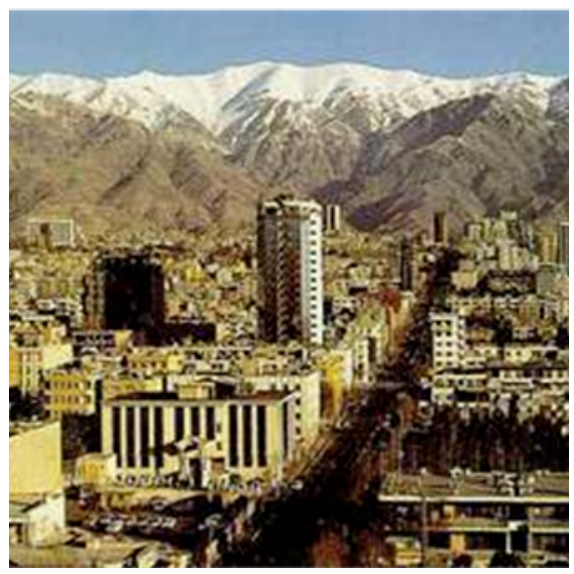

Figure 2. A view of Tehran, Iran (individual identity) (Hojat, 2005).

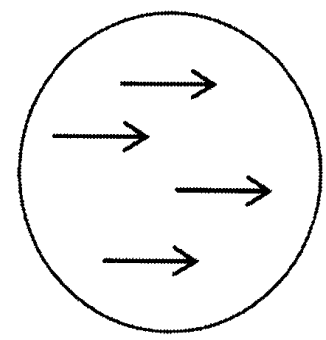

Figure 3. Traditional society: collective identity (Hojat, 2005). 


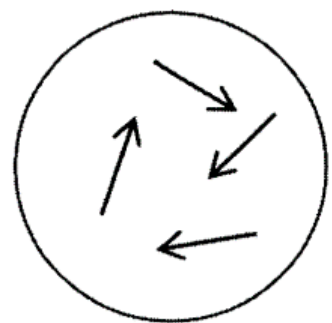

Figure 4. Modern society: individual identity (Hojat, 2005)

\section{NAQSH-E JAHAN SQUARE IN ESFAHAN, THE IDENTITY - CULTURAL ELEMENT IN ESFAHAN CITY REVIEW ON NAQSH-E JAHAN SQUARE FROM THE BEGINNING UP TO NOW}

Table 1. Developments of Naqsh-e Jahan square (Author).

\begin{tabular}{ccc}
\hline $\begin{array}{c}\text { Period of } \\
\text { times }\end{array}$ & Works \\
& Naqsh-e Jahan square was built as a \\
pre-designed space with an area about \\
505 meters length and 160 meters \\
width, and four markets was formed \\
on its four sides. This square has a \\
rectangular regular geometric plan \\
that extends to the north-south \\
direction. Four buildings were \\
constructed on the four corners of \\
Naqsh-e Jahan square including the \\
Ali Qapu Palace in the west as the \\
rule's center for the Shah, Qeysarie \\
gate in the north, Sheikh Lotfollah \\
Mosque in the east as an state- \\
religious (Shia) center and Masjed-e \\
Jameh Abbasi in the south of the \\
square that reflected social and \\
popular power. The outdoor plaza is \\
as a public space for many ceremonies \\
and costumes. \\
era \\
Changes have been occurred in all \\
aspects including health of buildings, \\
urban activities, as well as the \\
economic aspect was felt. Many \\
business units around the square were \\
closed down in the Qajar era. Zill al- \\
Sultan had made barracks by most of \\
cells of the square in the time to his \\
authority. Other factor in the Qajar \\
period that has made serious problems \\
for Naqsh-e Jahan square was \\
exhaustion and lack of repairing and \\
adequate protection of historic \\
buildings around the square.
\end{tabular}




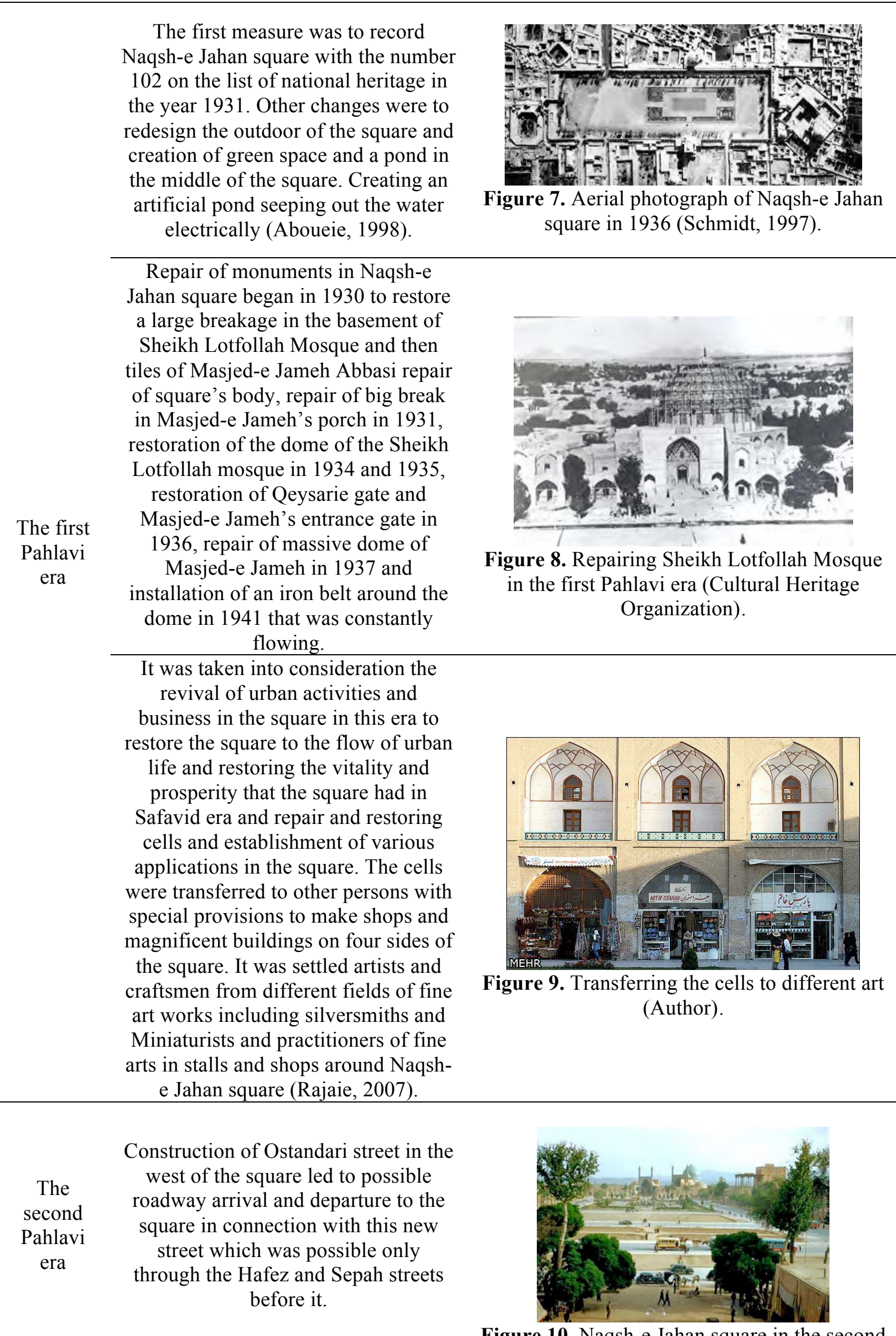

Figure 10. Naqsh-e Jahan square in the second 
Pahlavi era (Author).

\section{IDENTITY FACTORS OF NAQSH-E JAHAN SQUARE}

Naqsh-e Jahan's square is as Iranian relatively intact rare urban spaces which acted in the scale of the city and even beyond that, in the scale of Iran since its creation and today it is recognized on a global scale (Tavasoli and Bonyadi, 1992; Petersen, 1999). The date of building this square was about in 1632. It has about 510 meters length and 165 meters width. Idea of design and construction of Naqshe Jahan square was proposed and implemented in the period of Shah Abbas I, in the southwest of the Esfahan city as the city center (a city that was chosen as the new capital of Iran). This center, in fact, gives physical expression to organize the idea of unity and the relationship between main activities of the community by the name of religion. These activities with the main symbols of worship, teaching, politics, trade, manufacturing, sports and recreation, all were formed in the side or middle of the square where has been called Naqsh-e Jahan square and it was later known and become famous as the identity of Esfahan and Iran's Islamic civilization identity. Of course, formation of its body played a role worthy of attention with its certain symbolic elements and meanings in the reputation. What is called Qeysarie or market that was located on the north side with magnificent entrance has established many original elements of urban activities in that era such as inns, the Royal Mint, hospitals, mosques, timpani homes, hotels along with orders in the market (and various classes). At the same time, the focus on trade and economic and material activities had not gone people unnoticed to the human and religious values, and in addition to spiritual elements, it was met to care about modulation of the material activities and take the spiritual aspect to them. For example, revenues of four markets around Naqsh-e Jahan square were dedicated in the year 1638 by the Great Shah Abbas to the fourteen infallible Imams (Honarfar, 1984). On the other hand, the number of royal palaces such as Forty Columns and Eight Heavens and Ali Qapu palace made an extensive collection in the west of the square. Proximity of the field with the newly built Chaharbagh Street made it possible to link the square to the Zayanderud River and its beautiful beach which is finally linked to the beautiful Khaju and Si-o-seh Pol bridges and gardens of the south of the city. This square is one of the Iranian designed squares which has completely regular geometric shape and the establishment of each of the elements and operations of the middle have been predetermined and with prior planning. In addition to the fact that this feature introduces the square as an identity factor of Iran's civilization and represents it as a manifestation of Iranian art and science, it cancels the theory that the science and the field such as urban design is the newly-stranded alien and non-Iranian field with the argument that it has been taught in Harvard University as an academic discipline for the first time (with the conclusion that its principles should be taught from foreigners). This square that has very important position in almost all books and studies and reports that are dealt with Iran and the Islamic world, and even global works (with all their elements and the area around them and spatial organization) has been as a clear manifestation of Iranian knowledge to all sciences that are involved with shaping human living space (including architecture, urban designing, planning, environmental designing, engineering, side arts and different science and technologies). Some physical identifying factors of the square would be mentioned in this paper without entering on the principles and values and roots of formation of Naqsh-e Jahan square which needs independent and adequate discussion. Even in the physical factors, it won't be considered to enter to the architectural topics, or engage with characteristics of related arts (such as calligraphy and mosaic tile and woodcarving and tiling, etc.).

\section{THE BEAUTY}

Given the undeniable beauty of the square that has been concerned by all researchers and visitors in different ways and with different descriptions, it can be canceled some physical patterns that are proposed for the beauty of urban spaces. Physical proportions, and especially the proportions of height to width is one of these models in the urban areas. One of these ideas that has been proposed by Rob Carrier in the study of western squares is the proportional introduction in a specified range, so that middle of the range creates the enclosed (and beautiful and desirable) space. One side of the spectrum (the ratio of width to height is a large number as greater than 4:1) does not create an enclosed space primarily, and people feel lack of closeness and a sense of being in the desert in this space. It has been introduced the 3:1 ratio (about 18 degrees) as minimum sense of closure and a ratio of 2:1 (30 degrees) as the threshold of a sense of closure. The ratio of 1 to 1 is in the middle of the 
spectrum which is complete sense of closure in the study above and less ratio would press to mind the stifling atmosphere. It is noteworthy that this ratio (width to height ratio of the square's body) is about 10 to 1 in Naqsh-e Jahan square that provides non-enclosed space in terms of such studies and recommendations that cannot be called the square according to these studies. Even if we assume that this comment (feeling lack of closeness in the square) is correct, it has to see (that is the significant and important point) what arrangements the designer has used to transform this theory or the psychological principle that made the audiences to admire him and to induce its beauty and presence in enclosed urban space. Perhaps, one of the measures that have been used and has an impact on human perception was making four turning points in the middle of the four sides of square, especially two of which (mosques of Imam and Sheikh Lotfollah) were quite spiritual and the other (the headquarters of the King: Ali Qapu) was quasi-spiritual and the fourth (that was concerned by all people at least for half of living and its appearance) through which the designer could be able to overcome the proportion (Ahari, 2001). In addition, it was reduced the categorizing of the square's body to split members as well as to deploy daily needed applications for people in shops and by creating human scale (for walking) or considering the height or top of the wall ( Figure 11). In addition, the allocation of the middle of the square (at the time of creation) to the appealing activities (and not like as foreign works to sculptures and statues) has attracted the views towards the center preventing the observer from looking at the sky or the horizon (Figure 12).

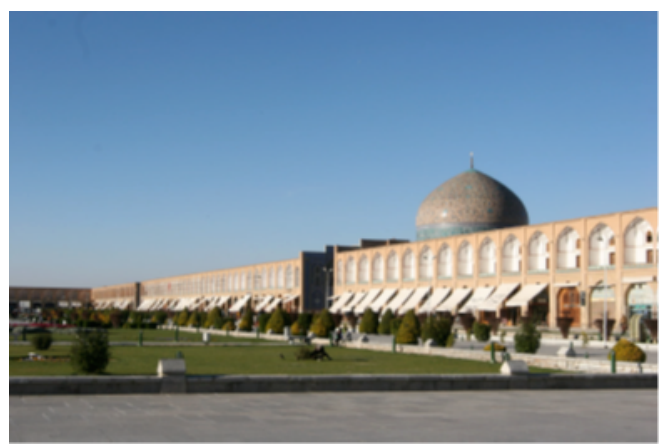

Figure 11. The eastern body of the square: row of shops, and attractive pedestrian environment for observers' eyes (Author)

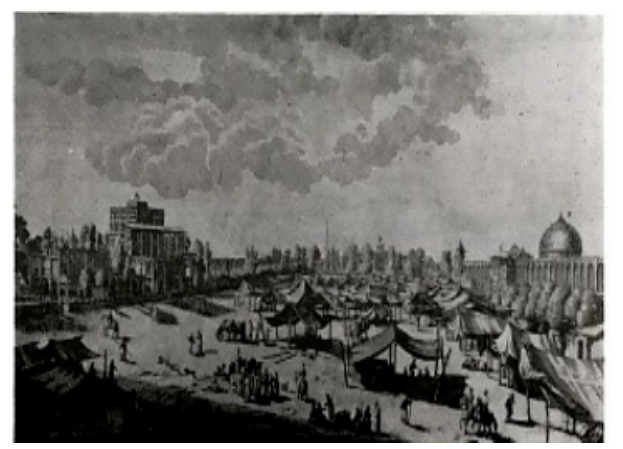

Figure 12. Naqsh-e Jahan square and some activities in the middle of the square in Safavid era (Author)

\section{THE PUBLIC SCENE OF THE SQUARE}

Although middle of the square has been welcomed the transformations from different directions since the construction so far, but what should be considered most is its character during the construction, and indeed knowledge to the Comments of designer and builder of the square. Probably the most accurate descriptions have been provided by tourists of that era on the Naqsh-e Jahan square. As an example, Adam Olearius (Head of the German delegation who traveled Iran at the time of Shah Safi, 1603-1671) wrote about the square of Esfahan, Iran, that: "the square of the city is broad having about seven hundred feet length and 200 feet width. Beautiful and uniform arch facades are built in the west that are dedicated to the goldsmith and jewelery with trees planted in front of them. There are broader arch facades in the east for playing Serena and drums. Saheb Al-Zaman mosque is in the south and the 
market is located in the north and sporting events are done in the center of square. High wall surrounds the king's palace and 3 to 4 persons protect it during days and 15 person at night"(Arianpour, 1974). Pietro Della Valle also said: "a full-water creek is running around the square that stones are placed in the middle of it for pedestrian traffic and it has been planted trees with foliage on the same straight line between the creek and shops that I think they will become the most beautiful view of the universe in the next few weeks when the leaves will form. The center of entire the square is carpeted by fine stone slabs and it does not exist better position for running or horseback riding" (quoted by Honarfar, 1984). It is observed that Della Valle has used terms of the most beautiful and best position for the square which these two features are related to the application of two live natural element groups of plants and water and gravel. There has been the media pools with the area of seventy feet and depth of ten feet with stone walls in front of market entrance and Imam Mosque that have always flowed clear water in them (Chardin, quoted by Honarfar, 1984). However, the stone pool in front of the Imam mosque is empty of water as a stone pit located on the observers' view (Figure 13). Chardin explained that the creek around the square is made with brick or black lime that is tougher. The 6-foot-wide creek with black stone plinth has pavement for four people who can easily move around besides each other. There is a 20 feet distance between the river and the surrounding rooms around the square (quoted by Honarfar, 1984). Therefore, one of the distinctive features of Naqsh-e Jahan square is the presence of nature in it (particularly water and plants) (Figure 14). This presence is represented also with simplicity and with a certain geometry that have been in the Iranian gardens. In addition, light and sky had the dominant presence on the square. The color of brick and soil increased also the presence of nature and human's sense to be much more connected with nature. One consequence of the presence in Naqsh-e Jahan square which is not observed as a certain complex except for two domes and palatial building that can be seen because of its prominence to the square due to relatively high length and width and low height of its wall (and of course, the entrance in distant cannot be seen easily) is the majority or feeling two issues for the human: the heavens and the earth and if it was in the Safavid era (and the space was preserved); perhaps an island surrounded by water was imagined to the mind and full shadow row of trees that were associated Heaven. What is that cannot be seen todays in the middle of the square and landscaping available indicates that is the repeat of patterns of the park. The center or middle of the square was dedicated also for holding various rituals, sport competitions and recreational displays and commercial caravan lodge. One of the main functions of the coffee houses around the square that are not existed today was discussing of poetry and stories and games and entertainment to praise Ali (AS) (Tavasoli and Bonyadi, 1992). In addition, there were illumination and decoration tools for holding celebrations and ceremonies gladly in the square. In addition, joy and gladness celebrations were as the main activities in the square as well as playing polo (Honarfar, 1984).

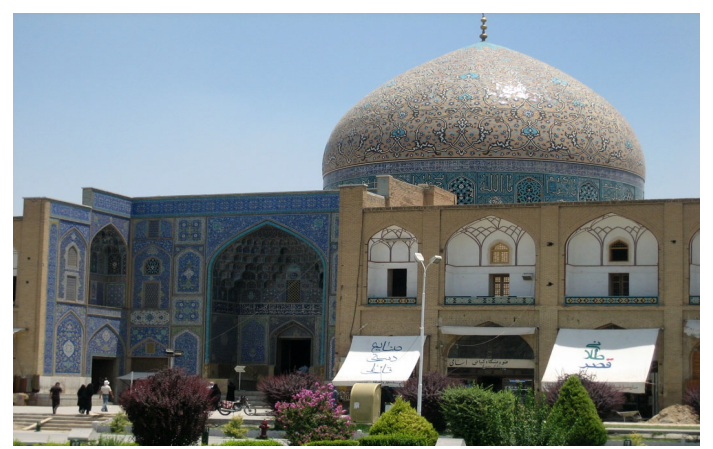

Figure 13. General view of the square in front of Imam Mosque towards the north (Author). 


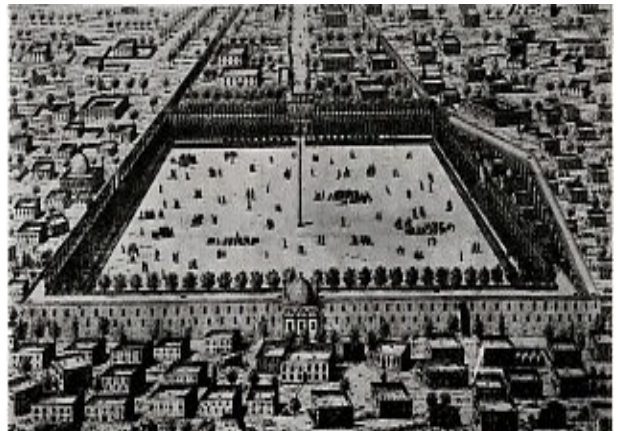

Figure 14. General view of Naqsh-e Jahan square in the Safavid era (empty middle and rows of trees and running water around) (Author).

\section{THE SQUARE'S BODY}

The square's body possesses cultural features and reveals valuable and spiritual matters that should not be neglected. The main body of the square on all four sides (but four main points that will be mentioned) in comparison with the size of the square is relatively short that in its early days, in the presence of an observer along one wall looking at the front side (especially in length) due to the observation of the earth) rock (along with current water movement on the right, the sense of presence in nature had been induced in observer due to seeing (stone) ground by flow of water around the square and by the presence of the rows of trees stretched to the sky in front of the walls, by observing the sky in much of the field of vision, and even by observing type, composition and color of materials (Figures 14, 15, and 16). In addition, pop-up frame of shops and porches on top of them that were repeated dozens of times have been appearance and reminders about mention. Mention (or repetition of sacred phrases or words), although perhaps seems boring by materialism thinking, but mention are valuable and beautiful with all its inner spiritual meanings in theologians thinking. The square's body has had beautiful unity and cohesion even in entries and inputs with its covering which was a rare example (in areas except for Iranian spaces). But about the milestones and observer's attention to the four sides of the square, it can be said that these four points are actually a manifestation of all the sacred and symbolic meanings in Islamic thought that can be explained for number four. Each of these four points is also dependent on each other and complement to each other in addition to their relative autonomy.

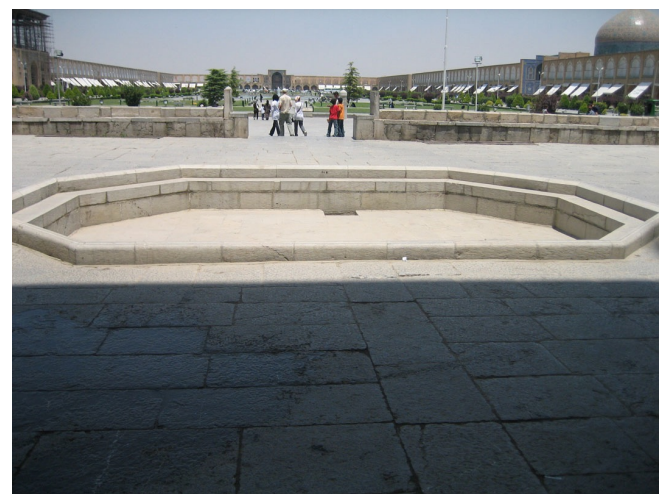

Figure 15. General view of the square, Sheikh Lotfollah Mosque (right), Ali Qapu (left), Qeysarie gate (face) and Imam Mosque (behind) (Author). 


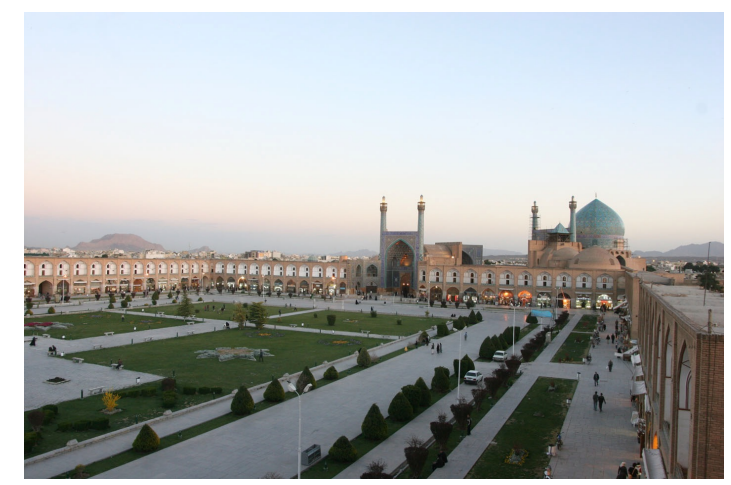

Figure 16. Location of Imam Mosque in the south of the square and its domination on the city (Author).

\section{SHEIKH LOTFOLLAH MOSQUE}

The mosque is located on the eastern side of the square in front of the Ali Qapu palace. It is from valuable works of architecture and Iranian art in terms of proportion, dome, light adjustment, motifs of tiles and spatial organization and other properties. According to the inscription of the entrance, the year of 1633 it began and its altar was ended in the year 1649. Characteristics can be outlined for the mosque which plays generally as distinguishes it from other Iranian mosques and schools including inside and outside mosaic tile and higher inscriptions in the line of Ali Reza Abbasi. Background color of tiles is often blue in other mosques, but it is buff in this mosque. The dome is as the most beautiful Iranian domes that there are fewer domes to compete with it in terms of color, geometrical forms and proportions by the simplicity and low height. A dome without any supplements (such as high entrance or finial to the heaven) which is alone on a wide open part of the city of Esfahan and the shadow covers it (Figures 11 and 17). The mosque is one of the exquisite and beautiful manifestations of Iranian culture and civilization by views of tourists and researchers and historians. For example, Pope wrote in the book of Iranian art evaluation that: a mosque that has been constructed on the east of Shah Square and opposite to the Ali Qapu Palace is one of the unique masterpieces of Iranian architecture. Sheikh Lotfollah Mosque on the other hand is not seen clearly except from the face (width) due to a point that has any direction (a circular dome) apparently and evens its entrance has indent from the square. This lack of induction of direction can be interpreted from verse 115 of alBaqarah Surah. In fact, with the cube that reaches the earth symbolizing the material world and the earth, and the dome over that that shadows the ground as the heaven, the mosque shows directionless induction of in the world of the soil and the sky in its exterior facets (Figure 18). While, inside the mosque makes the feeling to be in the center of the universe and being under the sky, it indicated the direction of the Qibla to the praise and worship with its beautiful altar in front of the entrance. Thus, although the space outside and around the mosque is apparently homogeneous, but inside and for worship, the space is polarized strongly and clearly as possible to the Kaaba. Sheikh Lotfollah Mosque has no apparent affinity with the vast majority of famous mosques is that are famous due to masterpiece architecture and it is appeared as an exception. This is why it cannot and should not be assessed and analyzed with general criteria and recognized rules (Tavasoli, 1992). Beautiful dome on a beautiful cube symbolizes the sky surrounding the earth and the souls that stem from the dome skylights into the radius of the sun evokes the sky with the stars decoration, and of course, the inscriptions of verses reminded and pointed the creator of the world. The movement of the cube (earth) to the center of the dome that appears to be central star, in fact, remind the beauty and serenity of tendency of matter to celibacy and the movement from the earth to the heavens and from the ground to sky that is a typical sample of Iranian art features as the abstractionism (Figure 18) (Naghizadeh, 2006b). Another feature of the mosque was forgetting the time (Tavasoli, 1995; Ardalan and Bakhtiar 1973). Such as forgetting or hiding place and direction. Here, it is not raised the North and South and East and West. Who were located under the dome of the mosque does not know or is not known where he is in the world. He sees only one direction by observing the mosque's altar, a direction to the center of the universe, the Qibla direction. On the other hand, he is appeared as the man, caliph of God as the center of the universe (under the dome) which is associated only with the Kaaba and the sky. Note that being of the human at the center of the universe here has distinct and 
substantial differences with being in the center in the modernism thought. Here, the man is under the rule of God in a temple compared with heaven and earth and as a caliph is on the house that its God has placed it as the center of the universe and the focus and worship. But in modern times, the man with the removal of God is considered as his successor and as the degree and measure of all things. In the spatial hierarchy of the mosque as well as spatial organization of the Imam Mosque (as will be mentioned) the height of the space that is called treatment space (Naghizadeh, 1999) has treated worshipers mind from worldly affairs and prepare him for prayer and worship, and at the same time, it shows itself clearly and competence with diverse manifestations. Space that such as Limbo links the world to the Hereafter, earth to the sky, material to the sense, invisible to attend and man to God. With the difference that this is done by so dark and narrow corridors in this mosque, and on the other else (Imam), it is through beautiful vestibule with corridors on either side.

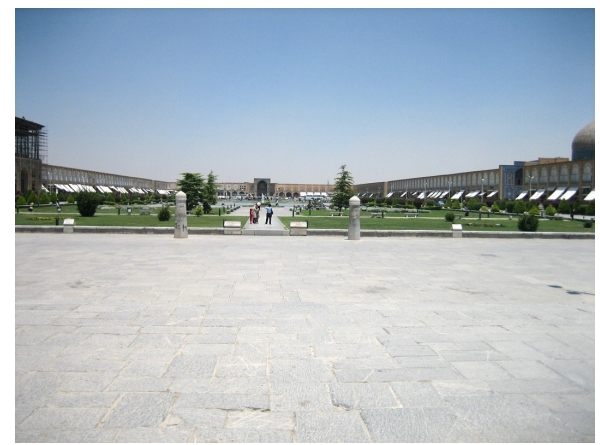

Figure 17. Sheikh Lotfollah Mosque as a gem on Naqsh-e Jahan square (Author).

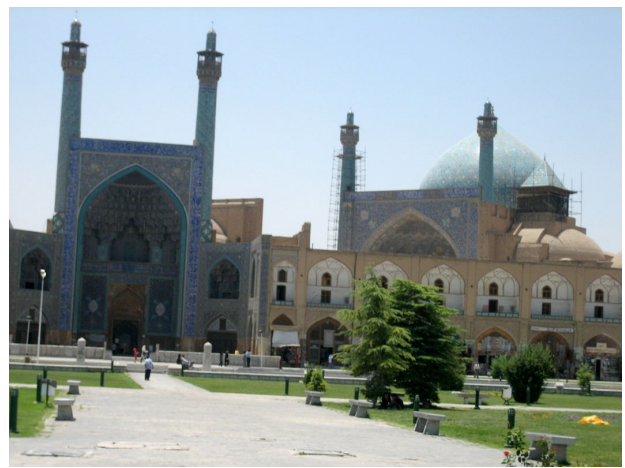

Figure 18. General landscape of Naqsh-e Jahan Imam Mosque

\section{IMAM MOSQUE}

Imam Mosque is also as valuable and magnificent works of Iranian and Islamic architecture, that its entrance was allocated to the center of the southern side of Naqsh-e Jahan square. In addition that there are many speeches on the architectural features and proportions and its technical high position, one of its distinguishing feature (which all researchers refer to it) is the lack of feeling the rotation of the square's axis to the direction of Qibla through the vestibule entrance and accessory hallways that goes toward it's beautiful courtyard when entering the mosque (Ahari, 2001). Perhaps this is true in an architectural study of the building, which it is, but let's see why that is, and what other ideas could also be raised. With regard to the fact that design of square and its surrounding complex was constructed outside the old city and by the absolute power of the (king) that had the power to choose any direction to for the square, why designers and builders of the square have not noticed to choose the direction of square with the Qibla not to appear this problem? And as somebodies claim exclusive effect of climatic issues, only climatic problems is the criterion of a naïve issue. With regard to the absolute power of Safavid king, relevance of scholars and philosophers and involvement of qualified and knowledgeable architects and artists, it seems that the set of considerations has led to select a direction with the angel from the Qibla. This selectivity results the perception that everyone is in the square would ask unconsciously by observing the mosque that why is that, and why the mosque axis is rotated than toward the square? and the answer: Islam was introduced and suggests the fundamental 
direction (Qiblah) in mind. On the other hand, consideration of the four minarets, which are placed two by two on a page that the resulting pages are rotated relative to each other, made it possible for the whole city to recognize the Qibla direction with regard to physical domination of the mosque to the entire city (at the time) (Figures 19 and 20) (Ahari, 2001).

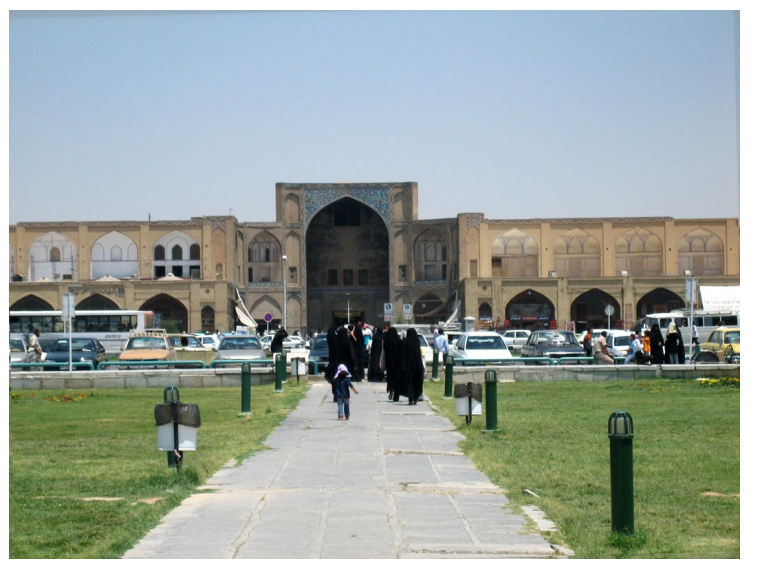

Figure 19. Ali Qapu, the protrusions on the square, cut of the second floor in the square's body on both sides, and the lack of walls on three sides of the second floor's wall and so on (Ahari, 2001).

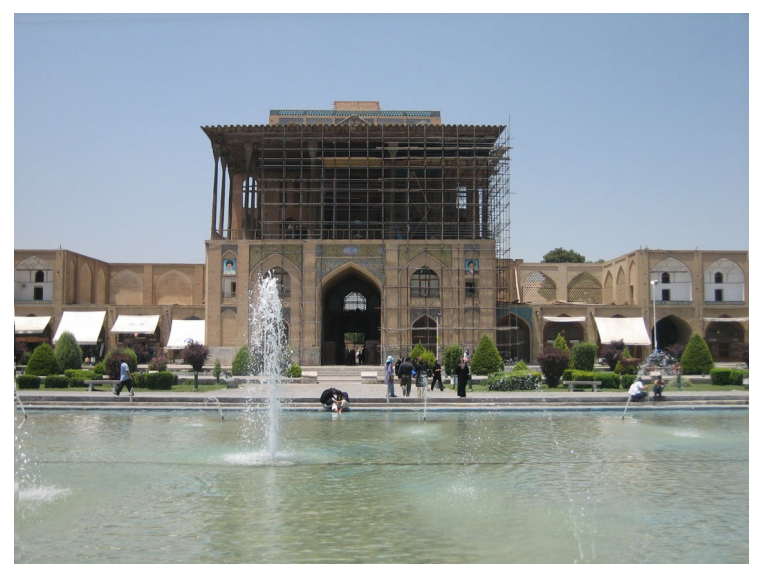

Figure 20. Qeysarie gate in the north of square, entering to the market in front of Imam Mosque's gate and on the other side of the square (Ahari, 2001).

\section{ALI QAPU PALACE}

The Palace is located in a third of southwestern side of the square and in front of Sheikh Lotfollah Mosque. Aside from what's mentioned on its technical and physical characteristics, it has features that some of them are mentioned. The building was mainly for receiving foreign ambassadors and as a place for monitoring what was happened in the square made up of halls overlooking the square and to enhance its performance, the other three main elements of the square (Imam and Sheikh Lotfollah mosques and the Qeysarie gate) were unlike of further from the body. In the meantime, this will be maybe due on the king's demand (or planners) to represent the king's power and status and even holiness (Tavasoli, 1992). On the other hand, the establishment of Ali Qapu in west of the square can be a reason for designer's shrewded emphasis field to represent decline in financial and material power, and this is in contrast with Sheikh Lotfollah Mosque in the east and align with the sunrise, and the Imam Mosque in direction of Qibla and the market in the north (Images 19, 13, 11 and 20) At the same time, Ali Qapu building, despite its holder that has no wall in the upper sides and just having column and roof for protecting the King and those around him from the harm of radiation and cold and heat, wind and rain has had no gravity and heaviness that impose itself on the square and the other buildings (Honarfar, 1984).

\section{MARKET}


There were relatively large troughs in the middle of the northern side of the square that its entrance is in front of the Imam Mosque entrance (in southern side) and the gate has pulled people into the city market that is the set of all production and trade activities and even schools and mosques and access roads to the city's residential neighborhoods. Although mentioning the separation of mosque and market and the necessity of focusing on the world and neglecting the hereafter, but still it is insisted on the fact that the world and the Hereafter are inseparable in a certain sense that are define by Islam (Tavasoli, 1992). Perhaps that is why the square is surrounded by market with all its spiritual properties, mosques' and schools' entrance are glaring alternatively in the market, and even central element connecting the spiritual elements of the square is the market that surrounds around the square (Map No. 11). Thus, in a word, it must be said of the unity of life and the importance of paying balanced attention to all its territories. But, the Qeysarie entrance is beautiful, stylish, elegant, inviting and having architectural value in its own that is appeared as a hole as if opening the mouth as a world to devour humans to merge those who focuses on it and unaware of spirituality and meaning and the Hereafter. But, there are those that can exit that hole in compliance with balance and consciousness after a while, business activity in it, as if to leave the world behind and got to the mosque. While expressing the unity of life and a notion of the need for dealing with the world to prepare for participation in the hereafter, the square will symbolically show that: to address the spirituality, it should to back up the world and vice versa, focus on the world life led to backing to the meaning and hereafter (Pirnia, 1990).

\section{CONCLUSION}

This article seeks identity as inherent, dynamic and progressive features of architecture. Distinction separates different architectures regardless of the characteristics of its users. Identifying is considered as independent todays which is added to it from the outside and by humans as autonomous and free contributor architecture. In viewpoints of scholars, human activities including architecture positions find meaning over time and in the place. Activities carried out in places create memories in the human mind over time which may be individually or collectively. With multiple references to them, collective memories that are as identifying elements in the human would stamp in his mind and makes the location different from other places. Considering the above, Naqsh-e Jahan square can be introduced as a sensible identity factor of Iranian civilization with its particular physical characteristics, with the four-sided elements, with its spatial organization, the spiritual meanings that induces the mind of the observer, with its history, with being famous, with arts and artifacts and techniques that are used in its creation, with the role that plays as an unique urban space, and with all of its internal and external attributes and characteristics. This identity factor is pointing to the ideology and thoughts and religion and culture of Iran and Iranians and is a representation of the Iranian scientific and artistic power noting a comprehensive approach in Iranians lives and way of life and that it can also be introduced as a genuine and not parodistic unique work compared with in urban areas in other civilizations. These are all lessons and guidance to the fact that the only original works that shaped by the original Iranian thought could be identity factor for the Iranian civilization and parodistic works as being great, majestic and ornate are imitative works and a foreign identity factor showing affectability and feelings of inferiority in the imitator society that destroys the spirit of creativity in the emulator community over time. Works of identity crisis that can be seen in various aspects in our society is the evidence of the issue. Hence, in today's architecture and urbanism, to achieve a stable identity should pay attention to past works and introduce all their features (clear and hidden) in order to strengthen the spirit of confidence in the community as the epigraph promise and to create the works that the time passing does not made it obsolescent and our posterity offer them as their identity factors in dealing with other civilizations by returning to themselves and pay attention to local and national characteristics attempting on framing that in the architecture and urbanism.

Imitation has squandered my head.

Two hundred damn with this imitation (Molavi)

\section{REFERENCES}


Aboueie R, 1998. The feasibility of restoring Naqsh-e Jahan square according to the current situation and past history. Master's thesis of repairing and restoration of historical monuments and contexts. School of Art, Campus of University of Esfahan.

Ahari Z, 2001. Isfahan School in Urban Planning, University of Arts.

Ardalan N, Bakhtiar L, 1973. The Sense of Unity. University of Chicago. Chicago.

Corbin H, 1994. History of Islamic Philosophy. Translated by Javad Tabatabaei. Desert Publications, Tehran, Iran.

Dehkhoda AA, 1999. Dictionary of Dehkhoda. Tehran University, Tehran, Iran.

Eghbali R, 1999. The identity of Iranian contemporary architecture: a comparative study of theories and experiences. PhD' thesis, Tehran University, Tehran, Iran.

Habibi M, 2004. From the flux to the city. Tehran University, Tehran, Iran.

Hojat I, 2005. Human making identity, identity processor human (reflection on identity and architecture). Fine Arts Magazine. 24. Tehran.

Honarfar L, 1984. Naqsh-e Jahan Square. Spikes publishing, Tehran, Iran.

Moin M, 1996. Moien dictionary. Amir Kabir Publications, Tehran, Iran.

Naghizadeh M, 1999. The mosque: a dominant frame over the Islamic complex. Islamic Conferences on Mosque Architecture: Past, Present, Future (vol. 2). University of Art, Tehran, Iran.

Naghizadeh M, 2006a. Islamic architecture and urbanism (theoretical foundations). Rahian Publications, Isfahan, Iran.

Naghizadeh M, 2006b. Foundations of religious art in Islamic culture: objective and physical manifestations. Rahian Publications, Isfahan, Iran.

Petersen A, 1999. Dictionary of Islamic Architecture. Routledge. London \& New York.

Pirnia MK, 1990. Iranian architecture methods. Islamic Art Publication, Tehran.

Rajaie A, 2008. Changes in urban development and management of Esfahan on the first Pahlavi era. Municipality Publishing Recreation and Cultural Organization, Esfahan, Iran.

Schmidt EF, 1997. Flight over the ancient cities of Iran. Translated by Arman Shishegar. Cultural Heritage Organization, Tehran, Iran (original version in 1936).

Shahabi-nejhad A, Aminzadeh B, 2002. The input perspective of Naqsh-e Jahan Square in Esfahan. Fine Arts Magazine. 17(1): 27-38.

Soltanzadeh H, 1991. Urban spaces in the context of historic Iran. Cultural Research Bureau, Tehran, Iran.

Tavasoli M, 1990. Principles and spaces of urban designing and residential areas in Iran (Vol. 1). Center for Urban Development and Architecture Studies and Researches, Tehran, Iran.

Tavasoli M, Bonyadi N, 1992. Urban space designing (1). Center for Urban Development and Architecture Studies and Researches, Tehran, Iran. 